\title{
Analysis and Experimental Study on Perforation Abnormity of Perforating Gun
}

\author{
Yu $\operatorname{Han}^{1, *}, M a \mathrm{Tao}^{2}$ \\ ${ }^{1}$ China Oilfield Services Limited (COSL) Tianjin Branch, No.1581, Hai Chuan Road, Tanggu Marine Hi-tech Development Area, \\ Binhai New District, Tianjin, China \\ ${ }^{2}$ Xi' an Wuhua Juneng Blasting Equipment Co., Ltd,20th Zhuque Avenue, Xi'an, China
}

\begin{abstract}
In the oilfield development, the perforation process is known as the "goal", therefore, the perforating operation is the most important process in the well completion process. However, in the perforating process, the perforating gun is working in the down hole; the operator cannot observe on the ground. And the perforating gun itself, and the perforating gun assemble process produced some unpredictable situation, such as broken blasting, gun broken, etc. These problems will influent the well completion process; even make the whole well scrapped. In this thesis, we will analysis one unpredictable situation in Bohai oilfield, through a variety of experiments to find and analyze the cause of the abnormal cases, to avoid the same problems in the future work.
\end{abstract}

\section{INTRODUCTION}

The Bohai oilfield in recent years due to anti-sand and fracturing, used 60 shots per meter (18SPF), this type of gun has the advantages of ultra-high density and big hole size, can satisfy the requirements of perforation process in fracture sandstone heavy oil well completion process, to effectively reduce the pressure near well, and production differential pressure in the same production quantity, to achieve stable sand control purpose. But in the process, due to the increased quantity of shaped charge, in the moment of perforating, the gun body also will have a lot of pressure, if in the assemble process have a problem, is likely to cause serious accidents of perforating gun ${ }^{[1][2]}$. This well the first TCP process on February 8th, 2014, after the process of running gun, depth correction and pressure firing, when lifting the gun, the operator found gun seized, after $180 \mathrm{Klb}$, the gun released; on the ground, the operator found the 9\# perforating gun occurred abnormal phenomenon (See Fig1,2) the rest of perforating gun perforated normal ${ }^{[3]}$.

\section{Figures and tables}

\subsection{Quality review}

Through the quality review of detonating cord in the process on this well (Type: 80RDXXHV, Lots No.: M1303), results: the material (powder), manufacture, testing and acceptance process were not found abnormal, the production process is under the quality control.

The Lot M1303 80RDXXHV detonate cord produced in December of 2013, this lot produced 47110.5 meters, at 7th of March of 2014, delivered 39072.5 meters, 20 boxes deliver to COSL. Others delivered to CPL Tuha, Bohai drilling, Shengli Logging, SPT Chongqing, GWDC Logging, etc. (see Table I). All users have not feedback abnormal information.

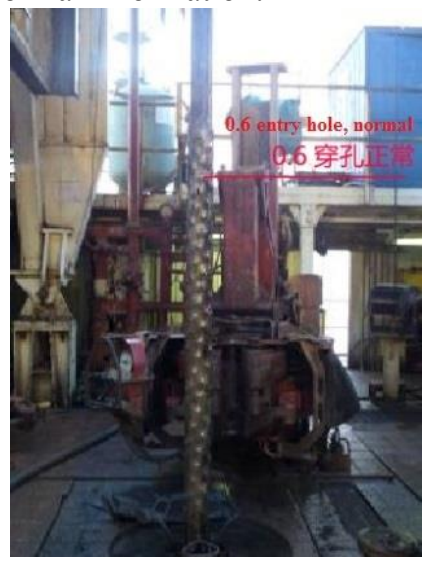

Fig1 9\# perforating gun lifting out of wellbore

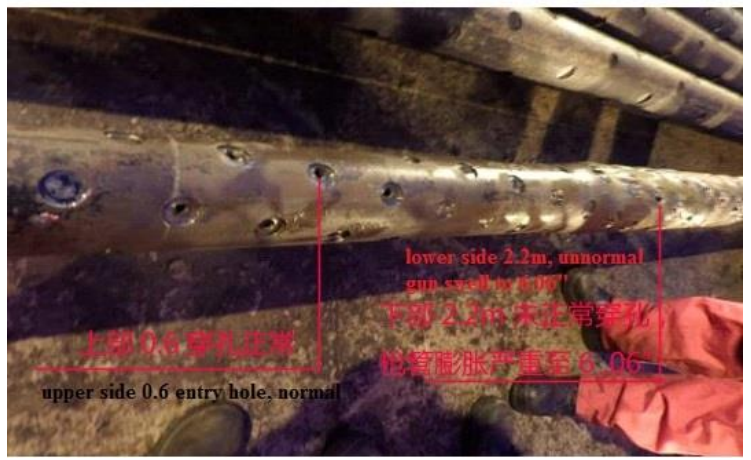

Fig2 entry hole of upper and lower side on perforating gun 
Table I Lot M1303 80RDXXHV delivery report

\begin{tabular}{|c|c|c|c|c|c|c|}
\hline Product & Type & $\begin{array}{l}\text { Lots } \\
\text { No. }\end{array}$ & Quantity & Date & Delivered to & $\begin{array}{c}\text { Delivered } \\
\text { qty }\end{array}$ \\
\hline \multirow{6}{*}{$\begin{array}{l}\text { Detonati } \\
\text { ng cord }\end{array}$} & \multirow{6}{*}{$\begin{array}{c}\text { 80RD } \\
\text { XXH } \\
\text { V }\end{array}$} & \multirow{6}{*}{$\begin{array}{c}\text { M130 } \\
3\end{array}$} & \multirow{6}{*}{$\begin{array}{c}47110.5 \\
\mathrm{~m}\end{array}$} & \multirow{6}{*}{$\begin{array}{c}20131 \\
2\end{array}$} & COSL & $3060 \mathrm{~m}$ \\
\hline & & & & & CPLTuha & $19890 \mathrm{~m}$ \\
\hline & & & & & Bohai Drilling & $2448 \mathrm{~m}$ \\
\hline & & & & & Shengli Logging & $3000 \mathrm{~m}$ \\
\hline & & & & & SPT Chongqing & $7767.5 \mathrm{~m}$ \\
\hline & & & & & GWDC Logging & $2907 \mathrm{~m}$ \\
\hline
\end{tabular}

\subsection{Establishment of fault tree}

Using failure mode analysis method, to analyze the possible cause of abnormal perforation of 9 \# perforating gun in this well. (see Fig 3).

The failure mode analysis (FAT) is using to find all causes of system failure, and combine the environments and state, after excluding the impossible cause ${ }^{[4]}$, to diagnose the final cause of the system failure.

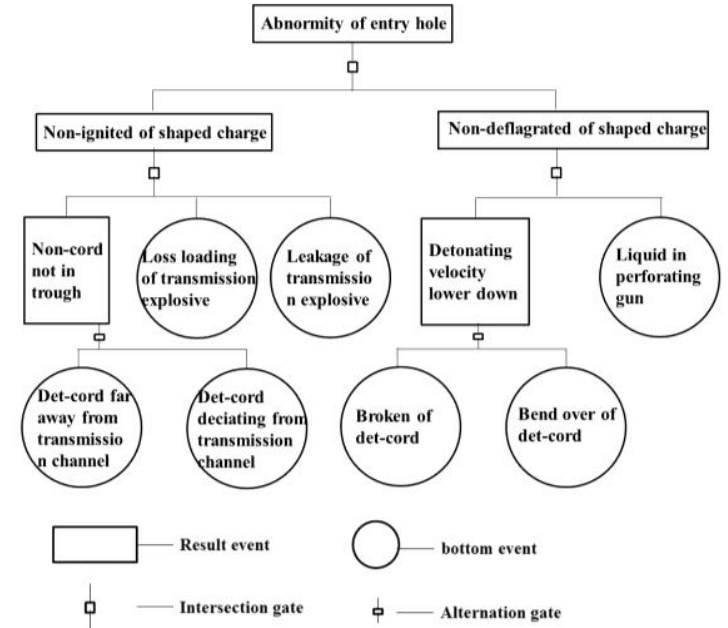

Fig 3 FAT of abnormity of entry hole

\subsection{Colour illustrations}

You are free to use colour illustrations for the online version of the proceedings but any print version will be printed in black and white unless special arrangements have been made with the conference organiser. Please check with the conference organiser whether or not this is the case. If the print version will be black and white only, you should check your figure captions carefully and remove any reference to colour in the illustration and text. In addition, some colour figures will degrade or suffer loss of information when converted to black and white, and this should be taken into account when preparing them.

\section{EQUIPMENT ANALYSIS}

\subsection{Shaped Charge}

If the shaped charge during the production process occurs: Booster missing load and booster leakage and other quality problems, caused reduce the sensitivity of shaped charge, when the shaped charge igniting caused detonating or burning, and shaped charge cannot shaped normal, resulting the abnormal perforation in perforating gun. The production of shaped charge is production line, if in production occurs missing load or leakage, the performance is discrete distribution. However, in the process $^{[5]}$, only 9\# perforating gun occurs abnormal perforation, and in the 9\# perforating gun occurs continuous 2.2 meters abnormal perforations, which can eliminate the shaped charge cause abnormal perforation.

\subsection{Detonating cord}

If the density of detonating cord is not enough, it may cause the lateral output shock wave to be insufficient to detonate the shaped charge, cause the shaped charge detonating or burning, The detonating cord is made up by powder, high strength Kevlar weaving layer, and nylon skin (see Fig 4), the main parameter affecting by the powder density.

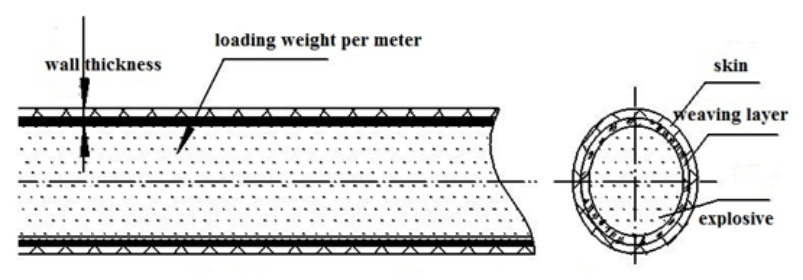

Fig4 Structure of detonating cord

The detonating cord production is product line, every mixing, knitting, extrusion and rolling will produce 800 meters, and because of ultra-high velocity detonating cord must be rolled to increase the density of powder. (see Fig 5). Now COSL using the detonating cord was produced by the product line which imported from Switzerland, this product line is automatic and can detect the density of detonating cord all the time, if occurs density abnormal in the product process, the equipment will alarm and stop automatically.

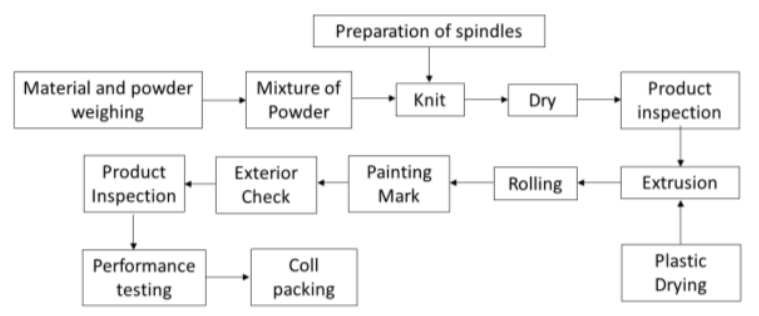

Fig5 manufacturing process of detonating cord

From the production process and acceptance of the detonating cord, no abnormality is found, and each detonating cord needs to be extracted to be test. The Lot M1303 80RDXXHV detonating cord accepted 128 units, the exterior check, outside diameter, density detection (design requirements: $\geqslant 17 \mathrm{~g} / \mathrm{m}$, the measure value: $18.36 \sim 22.76 \mathrm{~g} / \mathrm{m}$ ), detonating velocity test (design requirements: $\geqslant 7800 \mathrm{~m} / \mathrm{s}$, the measure value: $7831 \sim 8146 \mathrm{~m} / \mathrm{s}$,) etc., and all satisfy the design requirements. 
In Summary: Detonating cord density cause this problem in the operation is low.

\subsection{Some Common Mistakes}

\subsubsection{Detonating cord damage}

During the detonating cord assemble, if the detonating cord was damage, cause the density of powder reduce, the lateral output shock wave is insufficient to detonate the shaped charge, cause shaped charge detonating or burning ${ }^{[6]}$.

The detonating is protected by package during the delivery, is not easy to be damaged. In the loading gun process, is easy to be squeezed and bent by shaped charge which leads the change the density of the detonating cord. In the design of 60 shots per meter perforator, the detonating cord deviates from the centerline of the perforation gun $2.3 \mathrm{~mm}$, the distance of two adjacent shaped charges is $16.7 \mathrm{~mm}$, the detonating cord is repeated bending (60 times bending per meter) ${ }^{[7]}$. Under this condition, the detonating cord may be damaged and in extreme cases may lead to decrease the detonating velocity cause the detonation of detonating cord, lead the problem in this process. (see Fig 6,7)

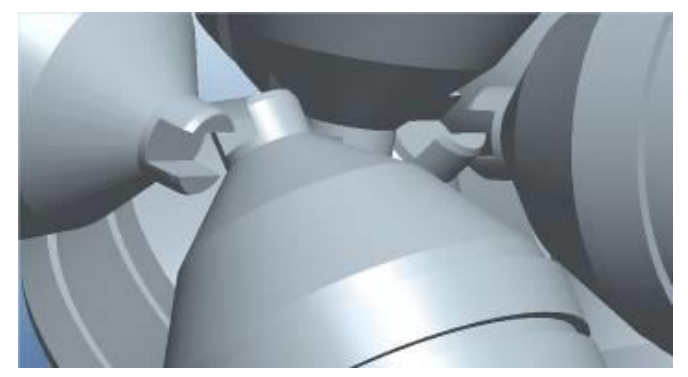

Fig 660 shot/m 127shaped charge loading simulation

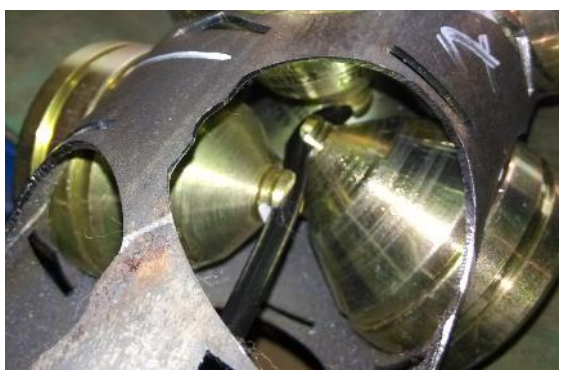

Fig 760 shot/m 127shaped charge loading in reality

\subsubsection{Detonating cord assemble}

During the assemble of detonating cord, such as: the detonating cord is not normally installed in the slot of the shaped charge, the bottom of shaped charge is on the detonating cord, or detonating cord is bypassed from the side of shaped charge ${ }^{[8]}$. May caused the detonation energy of detonating cord is lower, caused shaped charge detonating or burning.

\subsection{Perforating gun water seepage}

The liquid of well goes into the gun, it has a very big influence on the normal operation of the explosive device. Although in this process, the downhole pressures is not very high, but no eliminate the possibility of the seal is not good enough to lead the gun water seepage.

\section{TEST VERIFICATION}

According to the above analysis, the tests of the detonating cord and shaped charge under different conditions and verify.

\subsection{The experiments of broke outside and velocity in bend condition}

\subsubsection{The experiment method}

Harm the outside plastic layer of the detonating cord, and bend in the loading gun, at the same time of detonating, to test the velocity on input and output, to compare (see Fig 8 to 10 )

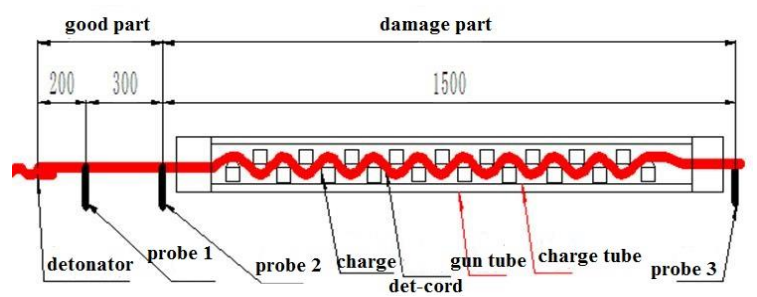

Fig 8 Test plan of broken skin and bend speed of detonating cord

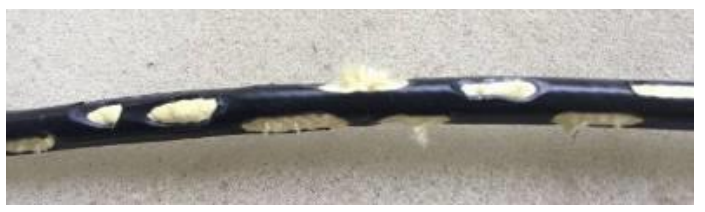

Fig 9 Status after broken

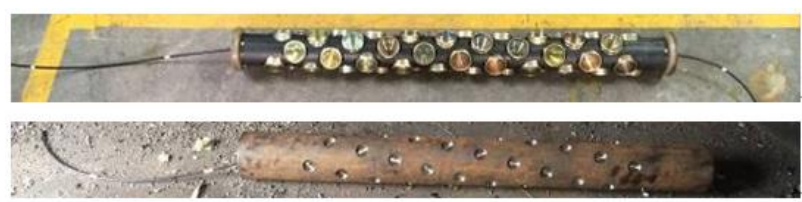

Fig 10 Status after loading

\subsubsection{The experiment result}

The detonating cord complete part, the velocity is $7913 \mathrm{~m} / \mathrm{s}$, the harm outside and bend detonating cord, the velocity is $8215 \mathrm{~m} / \mathrm{s}$.

\subsubsection{The experiment conclusion}


The detonating velocity of the 2 states is all in the high detonation velocity range, and it is not necessary to have problems in the current configuration of equipment, and also confirms the condition of use.

\subsection{The detonating cord away and deviated from blasting hole test}

\subsubsection{The experiment method}

In the assemble of shaped charge and detonating cord, according the normal installation, the bottom of shaped charge against the detonating cord, and detonating cord deviated the shaped charge, and record the each blind hole position ${ }^{[9]}$, observed the blind hole after detonating. The test quantity is 5. (see Fig 11)

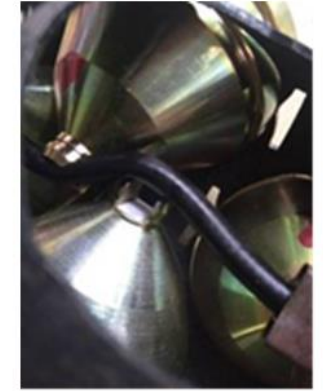

bottom of shaped charge against the detonating cord

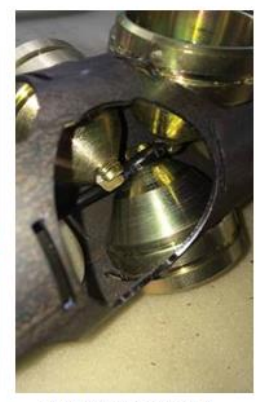

detonating cord deviated the shaped charge

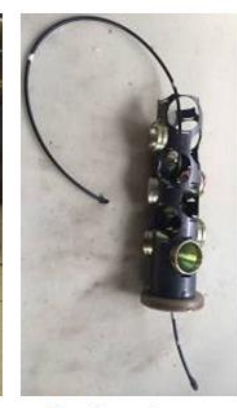

Perforating gun after load
Fig 11 Test Course

\subsubsection{The experiment result}

The normal assemble and shaped charge bottom against the detonating cord the performance is normal to perforating, the detonating cord deviated the shaped charge is not perforating. (see Fig 12)
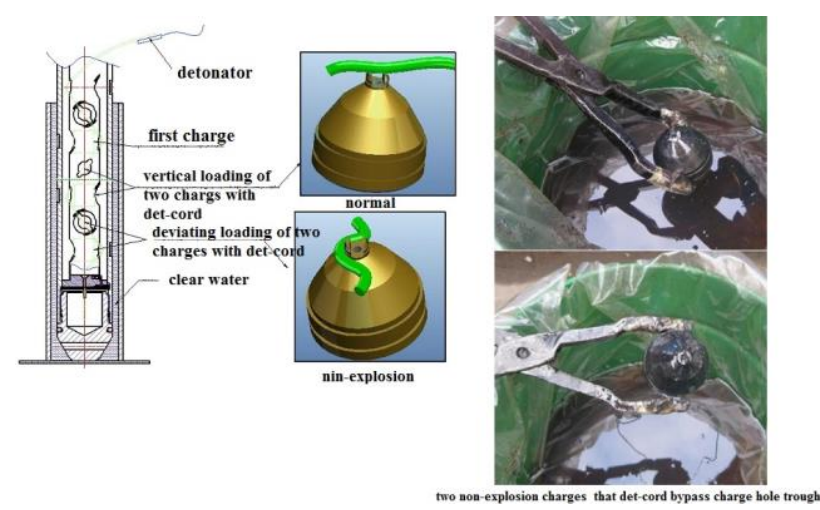

Fig 12 Test assembling and result

\subsubsection{The experiment conclusion}

When the detonating cord is slightly away from the detonation hole, the shaped charge can be detonated normal. No eliminate the possibility that the detonating cord deviated the detonation hole and caused shaped charge is not detonated.

\subsection{Simulation test of perforating gun water seepage}

\subsubsection{The experiment method}

According the normal loading gun condition to load 5 shaped charge, and put the 3 shaped charge of bottom side into the water after 3 hours, and detonate the perforating gun, to observe the gun body. (See Fig 13 to15)

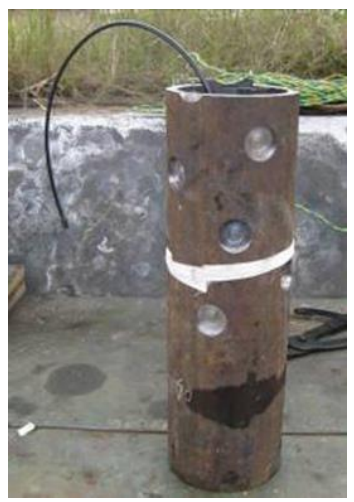

Fig 13 three charges at bottom end inwater in $3 \mathrm{~h}$

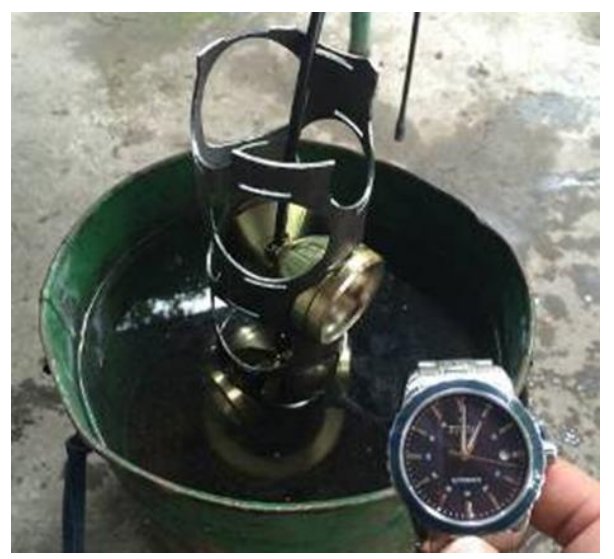

Fig 14 Test status

\subsubsection{Test Result}

perforating charges penetrated normally in air. Three perforating charges penetrated abnormally in water.(See Fig 16 to19).

\subsubsection{The experiment result}

2 shaped charge in the air perforating normal, 3 shaped charge in the water perforating normal. 


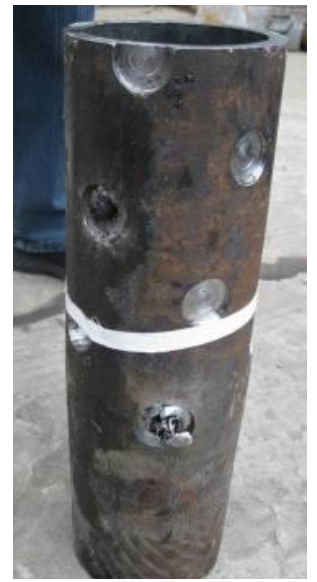

Fig 15 Status after test

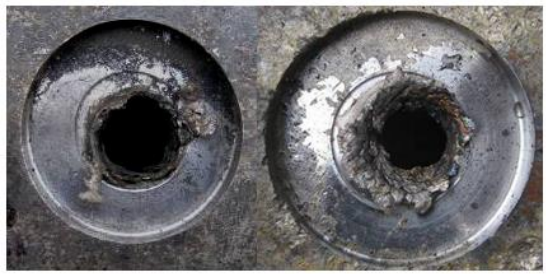

Fig 162 charges' normal entry hole

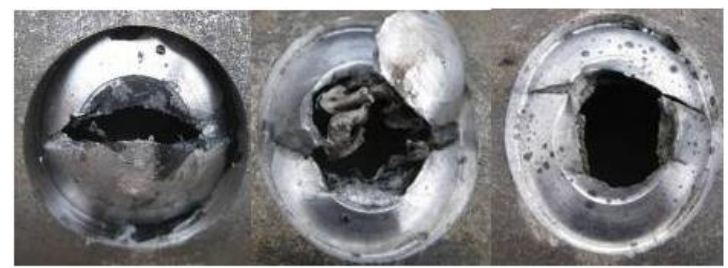

Fig 174 charges' un-normal entry hole

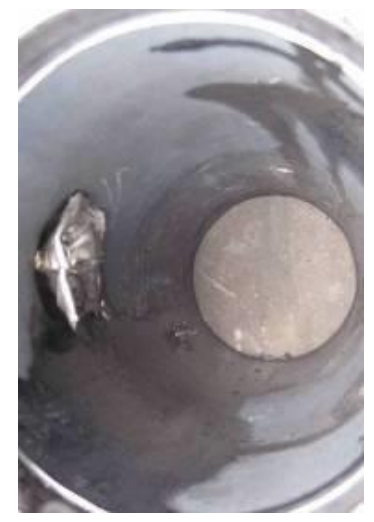

Fig 18 charge case being close to entry channel in un-normal condition

\subsubsection{The experiment conclusion}

If the perforating gun is water seepage, the shaped charge soaked in water after certain time, the water will goes into the powder, and shaped charge performance occurs abnormal phenomenon.

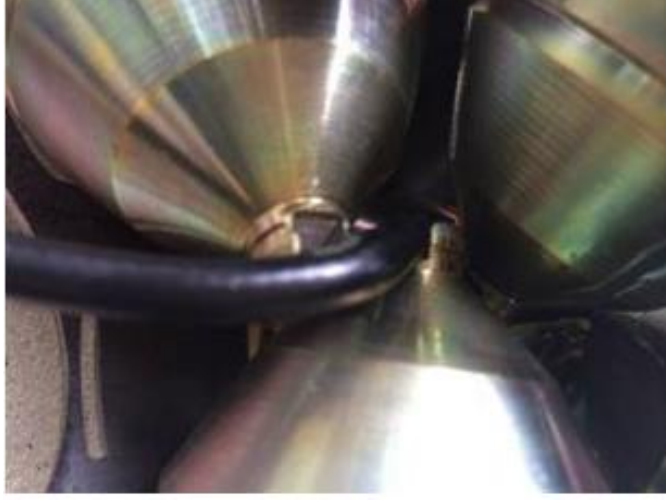

Fig 19 charge trough against to det-cord

\subsection{Initiation test of whole perforating gun without target}

\subsubsection{The experiment method}

1. When the gun loaded, the detonating cord is not processed and keeps the original condition, corresponding to the 27 shaped charges of top side 2. In the bottom side, the 26 shaped charges corresponding detonating cord, using cutter to break the outside skin, to expose the knitting layer, however ensure the power is not exposed, the damage is quite the same as the most serious damage when the gun is loading in the oilfield.

3 . The rest of detonating cord keeps complete.

4. To select the 1st, 2nd, 19th, 20th, 38th, 39th shaped charge form the igniting side, to vertical assemble the detonating cord and shaped charge ${ }^{[10]}$.

\subsubsection{The experiment result}

All perforations are normal. (See Fig 20 to 23)

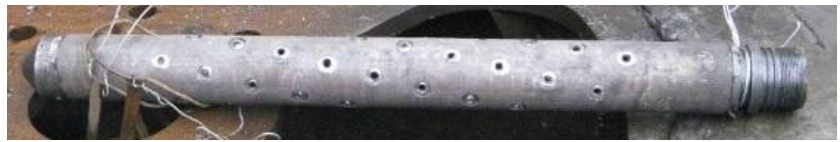

Fig 20 gun after perforating

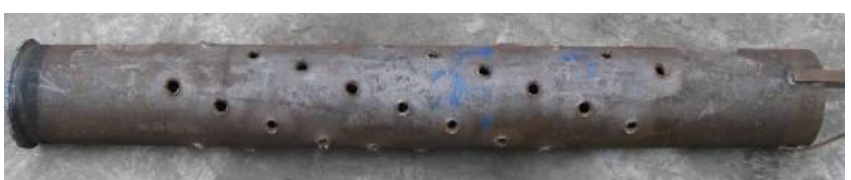

Fig 21 casing after perforating 


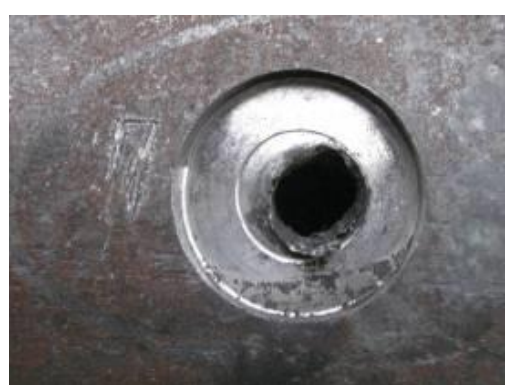

Fig 22 entry hole on gun tube after test

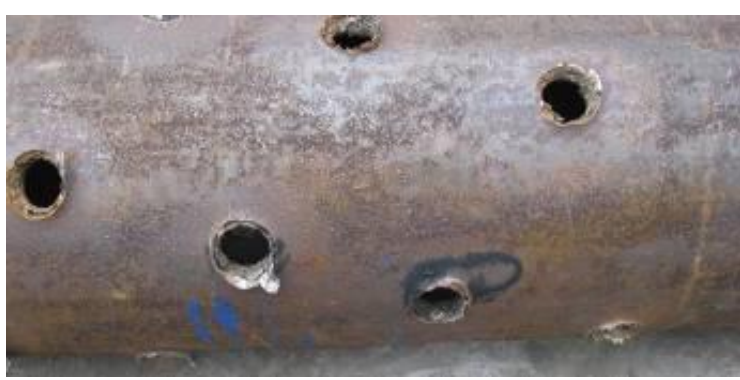

Fig 23 entry hole on casing after test

\subsubsection{The experiment conclusion}

The experiment did not simulate process problems.

\section{CONCLUSIONS}

1. According the fault tree analysis, the possible cause of gun bulge and no perforation mainly is four aspects: the quality of product, the bend damage of detonating cord, shaped charge abnormal load, and well liquid influence. 2. After quality review, we can eliminate the quality of product caused the problems.

3. Test the detonating cord under damage and bend condition, the explosive velocity is not decreased, although the test quantity is not big, but the result this reason caused the problem is less.

4. The abnormal installation of detonating cord and shaped charge could be a great influence the reliability of shaped charge.

5. Perforating the shaped charge that soaked in water, could cause gun bulged, not perforation, is similar to this process, cannot eliminate and also cannot be fully determined the water seepage cause the problem in this process.

6. Through statistical analysis, since 2011 , the 60 shot per meter 127 perforator the operation quantity is about 4000 meters, almost 200 thousands shaped charges, this problem is the first found, should be caused by accidental factors.

\section{References}

[1] Song SJ,Chen XB,Niu XX \& Yang YX,High Efficiency Composite Perforating Technology, Explosion and Shock Waves. 21,8-9 (2001)

[2] $\mathrm{Hu}$ MM, Zhu X,Present situation and trend of compound perforating technology, Explosion Materials. 31 (2017) 30-31.
[3] S.N.Domenico,HARNESSING THE GHOST, Abstracts of Beijing(89) International Symposium on Exploration Geophysics,.01 (1989) 20-23.

[4] Zhao ZX, Formulation development and characterization of cellulose acetate nitrate based propellants for improved insensitive munitions properties, Defence Technology. 02 (2014) 08-11.

[5] Cui JJ,Wang DY,Shi QQ, Structural Design Method on Elasticplastic of Oil Perforating Guns, Proceedings of 2010 International Conference on Computer,Mechatronics, Control and Electronic Engineering (CMCE 2010) Volume 3. 08 (2010) 12-15.

[6] Zhang HQ;Sun XP;Wang YZ;Yin JL;Wang CY Dynamic Numerical Simulation of Detonation Wave of Perforating Bullet and Research of Its Measuring Method, Proceedings of 2010 International Conference on Computer,Mechatronics, Control and Electronic Engineering (CMCE 2010) Volume 2. 08 (2010) 2832.

[7] T ManningJeffrey WK KlingamanViral PE RozumovJohn ,BM Wang, YS Patel, Enhanced propellant performance via environmentally friendly curable surface coating. Defence Technology. 06 (2017) 18-22.

[8] Wang,ZG, Application of Separable Perforating-Fracturing Combined Bullet to the Test of Oil and Gas Wells, Natural Gas Industry. 03 (1996) 01-05.

[9] Yang LL, Song DL, Shi X Study on Titanium Alloy TC4 Ballistic Penetration Resistance Part I:Ballistic Impact Tests, Chinese Journal of Aeronautics. 06 (2012) 12-16.

[10] Wu BY ; PU YouZhe ; YU XiaoYang ; SU WanHua ; Experimental Study on the Feasibility of Methane Drainage in Coal Seams with Compound Technique of Perforating and Fracturing, Engineering Sciences. 03 (2007) 09-12. 